\title{
Physiological Intracranial Calcifications - A Study in Coastal Karnataka
}

\author{
Krishna Kiran $\mathrm{S}^{1}$, Anston Vernon Braggs ${ }^{2}$ \\ ${ }^{1}$ Professor, Department of Radiodiagnosis, Father Muller Medical College, Mangaluru 575002, Karnataka, ${ }^{2}$ Senior Resident, \\ Department of Radiodiagnosis, Father Muller Medical College, Mangaluru 575002, Karnataka, India \\ Corresponding author: Dr.Anston Vernon Braggs, Department of Radio-Diagnosis, Father Muller Medical College, Father \\ Muller Road, Kankanady, Mangalore - 575 002, Karnataka, India
}

DOI: http://dx.doi.org/10.21276/ijcmsr.2020.5.1.22

(c) BY-NC-ND

How to cite this article: Krishna Kiran S, Anston Vernon Braggs. Physiological intracranial calcifications - a study in coastal Karnataka. International Journal of Contemporary Medicine Surgery and Radiology. 2020;5(1):A95-A98.

\section{A B S T R A C T}

Introduction: Several physiological intracranial calcifications have been described. With the advent of multidetector CT, these calcifications have become more visible. We aimed to study the prevalence of physiological intracranial calcifications in a tertiary care hospital in Coastal Karnataka.

Material and methods: A retrospective non-interventional study was conducted. 107 brain CT examinations were studied from September 2019 to October 2019 over a two month period. All studies were performed on a 128 slice CT scanner (General Electric Revolution). Images were reconstructed with $0.6 \mathrm{~mm}$ thickness. Apart from axial plane, images also studied in coronal and sagittal planes.

Results: Pineal calcifications were seen in $87 \%$, choroid plexus calcifications were seen in $85 \%$, habenula calcifications present in $12 \%$, petroclinoid ligament calcifications noted in $46 \%$, tentorium calcifiacitons noted in $4.6 \%$, falx calcifications noted in $14 \%$, superior sagittal sinus calcifications noted in $8 \%$, basal ganglia calcifications in $5 \%$ and temporal lobe calcifications in $1.8 \%$.

Conclusion: With advent of multidetector $\mathrm{CT}$, intracranial calcifications have become more visible.

Keywords: Intracranial, Physiological Calcification, Brain CT, Pineal Gland

\section{INTRODUCTION}

Physiological calcifications are unaccompanied by any evidence of disease and have no demonstrable pathological cause. ${ }^{1}$ They include calcifications of pineal gland, habenula, choroid plexus, falx, tentorium cerebelli, wall of superior sagittal sinus, temporal lobes. ${ }^{1,4}$ Most frequently, calcification of the pineal gland is noted, incidence of which is noted as the age increases. ${ }^{2}$ It is important to identify these physiological calcifications so as to not falsely call them as pathology, eg: haemorrhage. ${ }^{3}$

These calcifications are known to occur secondary to calcium deposition and less due to iron deposition in the vasculature of these structures. ${ }^{4}$ There are many modalities by which these calcifications can be examined, of which skull radiograph and ultrasonography have less sensitivity and specificity. ${ }^{4}$ Computed tomopgraphy (CT) and MRI are modalities by which intracranial calcifications can be examined, however CT is the gold standard. ${ }^{4}$

Incidence of these intracranial calcifications is not uniform, studies have shown varying pattern of intracranial calcifications. We wanted to assess prevalence of physiological intracranial calcifications on multislice CT in patients visiting our hospital.

\section{MATERIAL AND METHODS}

The study was conducted in Father Muller Medical college
Hospital Mangaluru Karnataka in the department of Radiodiagnosis. A total of 107 CT brains were studied retrospectively from September 2019 to October 2019 over a period of two months.

\section{Inclusion criteria}

All patients who underwent CT brain in the study period. Both genders and all age groups who underwent CT were included.

\section{Exclusion criteria}

Those with movement artifacts where images were not diagnostic.

Patients with metallic artifacts where excluded from the study.

Extra neuroparenchymal calcifications were excluded, for eg: Intraocular calcifications, tonsiloliths etc.

Those with intracranial tumors in pineal region.

\section{CT Protocol}

CT was done with patient in supine position in 128 slice multidetector CT. $0.6 \mathrm{~mm}$ thickness images were reconstructed. Images of brain were acquired parallel to orbito-meatal line. Only non-contrast images were selected for purpose of study.

Calcification was defined as hyperattenuating material in respect to gray matter. Most of patients were referred for suspected intracranial injury or stroke. Many of these 
patients were detected to have intracranial hemorrhages, calcifications were differentiated from hemorrhages by using the cut off of $100 \mathrm{HU}$, hemorrhages have a HU of $40-60 .^{4}$ Calcifications were examined in various areas such as the pineal gland, habenula, choroid plexus, petro-clinoid ligament, tentorium, falx, superior sagittal sinus, basal ganglia and temporal lobe.

\section{STATISTICAL ANALYSIS}

Descriptive statistics, mean and percentages were used for analysis.

\begin{tabular}{|l|c|c|c|}
\hline Age group & Male & Female & Total \\
\hline 0-9 years & 01 & 01 & 02 \\
\hline 10-19 years & 12 & 0 & 12 \\
\hline 20-29 years & 16 & 05 & 21 \\
\hline 30-39 years & 14 & 03 & 17 \\
\hline 40-49 years & 09 & 05 & 14 \\
\hline $50-59$ years & 15 & 03 & 18 \\
\hline $60-69$ years & 06 & 05 & 11 \\
\hline $70-79$ years & 06 & 02 & 08 \\
\hline $80-89$ & 03 & 0 & 03 \\
\hline $90-99$ & 01 & 0 & 01 \\
\hline \multicolumn{4}{|l|}{ Table-1: Depicting age and sex distribution of study population } \\
\hline
\end{tabular}

\begin{tabular}{|c|c|c|c|c|c|c|c|c|c|}
\hline Age group & pineal & $\begin{array}{l}\text { Choroid } \\
\text { plexus }\end{array}$ & habenula & $\begin{array}{l}\text { Petroclinoid } \\
\text { ligament }\end{array}$ & tentorium & falx & $\begin{array}{c}\text { Superior } \\
\text { sagittal sinus }\end{array}$ & $\begin{array}{c}\text { Basal } \\
\text { ganglia }\end{array}$ & $\begin{array}{c}\text { Temporal } \\
\text { lobe }\end{array}$ \\
\hline $0-9$ years & - & - & & & & & & & \\
\hline \multicolumn{10}{|l|}{$10-19$ years } \\
\hline $20-29$ years & 5 & 5 & - & 2 & & & 1 & & \\
\hline 30-39 years & 3 & 3 & & & & 1 & & 1 & \\
\hline 40-49 years & 4 & 5 & & 2 & & 1 & & 1 & \\
\hline 50-59 years & 3 & 3 & 1 & 2 & & 1 & 1 & & \\
\hline 60-69 years & 5 & 5 & 1 & 03 & & 1 & & 1 & 1 \\
\hline 70-79 years & 2 & 2 & & & & & & 1 & \\
\hline \multicolumn{10}{|l|}{$80-89$ years } \\
\hline \multicolumn{10}{|l|}{ 90-99 years } \\
\hline & $91 \%$ & $95 \%$ & $8.3 \%$ & $37 \%$ & $0 \%$ & $16 \%$ & $8 \%$ & $16 \%$ & $4 \%$ \\
\hline
\end{tabular}

\begin{tabular}{|c|c|c|c|c|c|c|c|c|c|}
\hline Age group & Pineal & $\begin{array}{l}\text { Choroid } \\
\text { plexus }\end{array}$ & Habenula & $\begin{array}{l}\text { Petroclinoid } \\
\text { ligament }\end{array}$ & tentorium & falx & $\begin{array}{c}\text { Superior } \\
\text { sagittal sinus }\end{array}$ & $\begin{array}{l}\text { Basal } \\
\text { ganglia }\end{array}$ & $\begin{array}{c}\text { Temporal } \\
\text { lobe }\end{array}$ \\
\hline \multicolumn{10}{|l|}{$0-9$ years } \\
\hline $10-19$ years & 7 & 2 & 1 & 1 & & & & & \\
\hline 20-29 years & 16 & 14 & 1 & 12 & & 2 & 1 & & \\
\hline 30-39 years & 13 & 14 & 2 & 9 & 1 & 1 & 1 & 1 & \\
\hline $40-49$ years & 8 & 9 & 4 & 1 & & & 1 & 1 & \\
\hline 50-59 years & 14 & 15 & & 7 & 1 & 5 & 1 & & \\
\hline 60-69 years & 4 & 5 & & 3 & & 1 & 1 & & 1 \\
\hline 70-79 years & 6 & 6 & 1 & 5 & 1 & 1 & & & \\
\hline $80-89$ years & 3 & 3 & 1 & 3 & 1 & 1 & 1 & & \\
\hline \multirow[t]{2}{*}{ 90-99 years } & 1 & 1 & 1 & & 1 & 1 & 1 & & \\
\hline & $86 \%$ & $83 \%$ & $13 \%$ & $49 \%$ & $60 \%$ & $14 \%$ & $8.4 \%$ & $2.4 \%$ & $1.2 \%$ \\
\hline
\end{tabular}

Figure-1: Plain axial sections of $\mathrm{CT}$ brain depicts pineal calcifications. Arrows mark site of pineal calcifications.

107 CT brains were studied. Of these 83 (77.5\%) were males and 24 (22.4\%) were females. Age range varied from 03 to 93 years. Pineal calcification was seen in $87 \%$, choroid plexus calcification noted in $83 \%$, Habenula calcifications noted in $12 \%$,petroclinoid ligament noted in $46 \%$,tentorial in $1.8 \%$

Pineal calcification was detected earliest at 16 years, whereas choroid plexus calcification was detected earliest at 12 years.

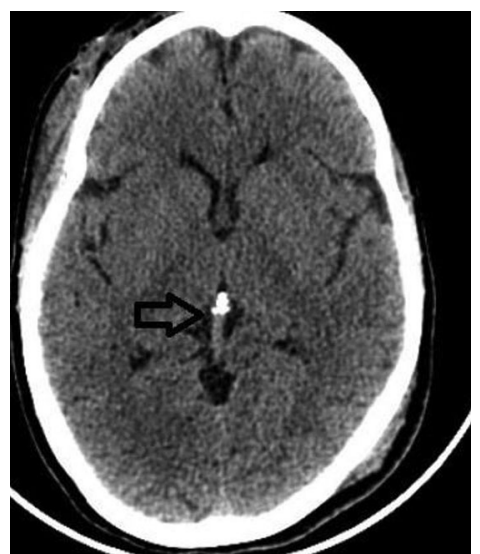
\begin{tabular}{|c|c|c|c|c|} 
tentorium & falx & Superior & Basal & Temporal
\end{tabular} 


\begin{tabular}{|c|c|c|c|c|c|c|c|c|c|}
\hline Age group & Pineal & $\begin{array}{l}\text { Choroid } \\
\text { plexus }\end{array}$ & habenula & $\begin{array}{l}\text { Petroclinoid } \\
\text { ligament }\end{array}$ & tentorium & falx & $\begin{array}{c}\text { Superior } \\
\text { sagittal sinus }\end{array}$ & $\begin{array}{l}\text { Basal } \\
\text { ganglia }\end{array}$ & $\begin{array}{c}\text { Temporal } \\
\text { lobe }\end{array}$ \\
\hline \multicolumn{10}{|l|}{$0-9$ years } \\
\hline $10-19$ years & 7 & 2 & 1 & 1 & & & & & \\
\hline 20-29 years & 21 & 19 & 1 & 14 & & 2 & 2 & & \\
\hline 30-39 years & 16 & 17 & 2 & 9 & 1 & 2 & 1 & 2 & \\
\hline 40-49 years & 12 & 14 & 4 & 3 & & 1 & 1 & 2 & \\
\hline 50-59 years & 17 & 18 & 1 & 9 & 1 & 6 & 2 & & \\
\hline 60-69 years & 9 & 10 & 1 & 6 & & 2 & 1 & 1 & 2 \\
\hline 70-79 years & 8 & 8 & 1 & 5 & 1 & 1 & & 1 & \\
\hline $80-89$ years & 3 & 3 & 1 & 3 & 1 & 1 & 1 & & \\
\hline \multirow[t]{3}{*}{ 90-99 years } & 1 & 1 & 1 & & 1 & 1 & 1 & & \\
\hline & 94 & 92 & 13 & 50 & 5 & 16 & 9 & 6 & 2 \\
\hline & $87 \%$ & $85 \%$ & $12 \%$ & $46 \%$ & $4.6 \%$ & $14 \%$ & $8 \%$ & $5 \%$ & $1.8 \%$ \\
\hline
\end{tabular}

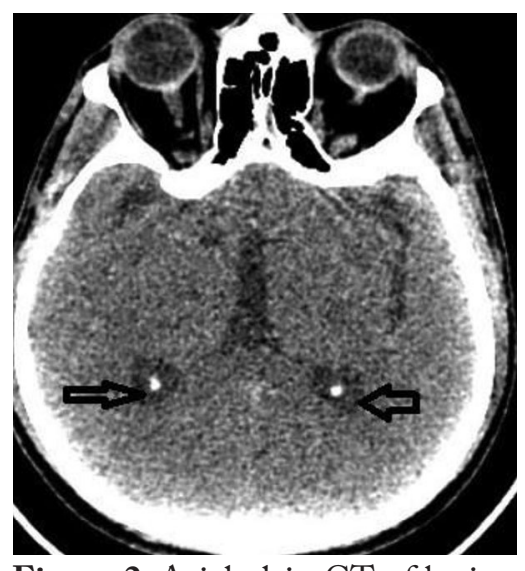

Figure-2: Axial plain CT of brain, arrows point to choroid plexus calcifications

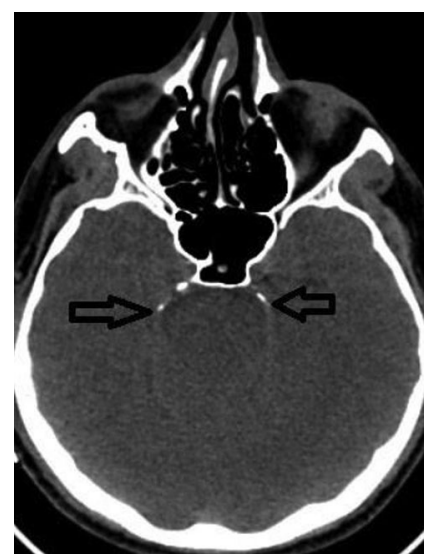

Figure-3: Plain CT brain axial sections, arrows point to petroclinoid ligament calcifications.

Increasing incidence of intracranial calcifications were detected with advancing age.

Table 1 depicts age and sex distribution of study population. There were 83 males and 24 females in the study. Table 2 depicts incidence of intracranial physiological calcifications in females in various sites. Highest incidence was pineal (91\%) and choroid plexus (95\%) calcifications. Table 3 depicts incidence of intracranial physiological calcifications in males in various sites. Highest incidence was pineal (86\%) and choroid plexus (83\%). Table 4 depicts incidence of intracranial physiological calcifications in males and females together. Similarly highest incidence was pineal (87\%) and choroid plexus (85\%). Figure 1 depicts pineal calcifications, figure 2 reveals choroid plexus calcifications and figure 3 shows petroclinoid ligament calcifications.

\section{DISCUSSION}

Physiologic intracranial calcifications are common, however different authors have described varying incidence of physiologic calcifications.

Kwak et al studied intracranial calcifications in consecutive 2877 patients on several $3^{\text {rd }}$ generation CT scanners at Ishikawa Japan. ${ }^{2}$ They described incidence of pineal calcifications as $67 \%$ in pineal gland, $57 \%$ in choroid plexus and $7.5 \%$ in basal ganglia.

Daghighi et al studied intracranial calcifications in Tabriz, Iran. ${ }^{1}$ Total 1569 patients were included in the study. They also used $3^{\text {rd }}$ generation CT scanner and used 5/10 mm thick slices. Incidence of pineal calcifications was $71 \%, 66 \%$ choroid plexus, 20\% Habenula, 7.3\% tentorium cerebelli,sagittal sinus or falx cerebri and $0.8 \%$ basal ganglia calcifications.

Som et al studied intracranial calcifications in Kolkata India. ${ }^{3}$ They included $100 \mathrm{CT}$ studies and did study on a 64 slice multidetector CT. Pineal calcifications was seen on $62 \%$, choroid plexus calcifications was seen in 54\%, dura mater calcifications noted in $26 \%$ and basal ganglia calcifications present in $8 \%$.

Bora et al studied intracranial calcifications in Pondichery India. ${ }^{4}$ They included 1537 subjects and study was done on a 16 slice multidetector row CT. They found incidence of pineal calcifications at $72.4 \%$, choroid plexus calcifications at $68 \%$, habenular calcifications at $20 \%$,falx calcifications at $1.4 \%$ and basal ganglia calcifications at $1.1 \%$.

We studied intracranial calcifications on an ultramodern 128 slice CT scanner with submillimeter reconstruction (0.6 mm).Pineal calcification was seen in $87 \%$, choroid plexus calcification noted in $83 \%$, habenula calcifications noted in $12 \%$,petroclinoid ligament noted in $46 \%$,tentorial calcification in $4.6 \%$ and temporal lobe calcification noted in $1.8 \%$.

The incidence of intracranial calcifications is quite high in our study compared to other studies. This can be attributed 
to increasing sophistication of CT machines and regional variation. Whitehead et al stated that pineal calcifications are seen in increasingly in younger age group ${ }^{5}$, as previous studies were conducted in primitive CT scanners with thicker CT sections. Bora et al also found higher incidence of pineal and choroid plexus calcifications from Pondichery India. ${ }^{4}$

We also have noted high incidence of petroclinoid ligament calcification. A detailed study of skull base ligamentous mineralization by Touska $\mathrm{P}$ et al showed similar evidence of mineralization in $58.3 \%$ of patients. ${ }^{6}$

Amongst all intracranial calcifications, pineal calcifications have been studied in detail. Zimmerman et al in 1982 stated that pineal calcifications in patients less than 6 years should be viewed with suspicion ${ }^{7}$ However this study was done in 8 $\mathrm{mm}$ thick sections. Whitehead et al state that this is no longer true in modern CT era and incidence of pineal calcification in young children ( $0-9$ years) in their study was $5 \%$. In our study pineal calcification was found as early as 10 years.

Uduma et al studied intracranial calcifications in central Africa, ${ }^{8}$ highest incidence was found $56 \%$ in choroid plexus. They used a single slice scanner with 2 and $5 \mathrm{~mm}$ thick sections. Similar study by Adamassie D et al in 2009 showed incidence of pineal calcifications at $72 \%{ }^{9}$ and choroid plexus calcifications at $43.3 \%$.

Largest study till date for intracranial calcifications was done by Yalcin et al. ${ }^{10}$ They studied 11,941 subjects using a combination of 4 row and 64 row CT scanners. They found a prevalence of $71.6 \%$ for pineal calcifications and of $70.2 \%$ for choroid plexus calcifications. These are similar to our findings and we believe use of advanced CT scanners and local variations have contributed for relatively higher incidence of intracranial calcifications.

\section{CONCLUSION}

There is a need to know regional variations in incidence of intracranial calcifications. Increasing sophistication in CT technology is detecting higher prevalence of physiological intracranial calcifications.

\section{REFERENCES}

1. Daghighi M. H, Rezaei V, Zarritan S, Pourfathi H. Intracranial physiological calcifications in adults on computed tomography inTabriz, Iran. Folia Morph (Warsz) 2007;66(2):115-9.

2. Kwak R, Takeuchi F, Ito S, Kadoya S Intracranial physiological calcification on computed tomography (Part 1): Calcification of the pineal region. No To Shinkei 1988;40(5): 569-57

3. Som. P, S. Datta, A. Saha, A. Ghosal. A study of physiological intracranial calcification on CT scan in eastern Indian population. J Anat Soc India 2015;64(5):s23-s26.

4. Bora M, Kaveri S, Vithiavathi S, Siddhartha, Moidu $\mathrm{F}, \mathrm{Vignesh} \mathrm{M}$ et al. Incidence and distribution of normal intracranial calcifications in adults on computed tomography. Int J Sci Res. 2015;4(3):23-29.

5. Whitehead MT, Oh C, Raju A, Choudhri AF. Physiologic pineal region, choroid plexus, and dural calcifications in the first decade of life. AJNR. 2015;36(3):575-580
6. Touska, P., Hasso, S., Oztek, A. ChinakaF, Connor F. Skull base ligamentous mineralisation: evaluation using computed tomography and a review of the clinical relevance. Insights Imaging 2019;10(55):23-29.

7. Zimmerman RA, Bilanuik LT. Age related incidence of pineal calcifications detected by computed tomography. Radiology 1982; 42(1): 659-62

8. Uduma FU, Pius F, Mathieu M. Computed tomographic pattern of physiological intracranial calcifications in a city in central Africa. Glob J Health Sci. 2011;4(1):184191.

9. Admassie D, Meckonnen A. Incidence of normal pineal and choroid plexus calcification on brain $\mathrm{CT}$ at Tikur Anbessa Teaching Hospital Addis Ababa Ethiopia. Ethiop Med J 2009:47(1);55-60.

10. Yalcin A, Ceylan M, Bayrakutan OF, Sonkaya AR, Yue. Age and gender related prevalence of intracranial calcifications in CT imaging. J chem Neuroanat 2016,78(4):20-24.

\section{Source of Support: Nil; Conflict of Interest: None}

Submitted: 26-12-2019; Accepted: 28-01-2020; Published online: 19-02-2020 